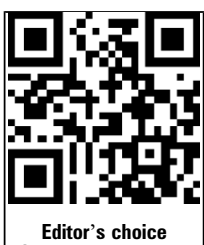
Editor's choice
Scan to access mor free content

- Additional material is published online only. To view please visit the journal online (http://dx.doi.org/10.1136/ bjsports-2015-095424)

${ }^{1}$ Faculty of Health Sciences, Clinical and Rehabilitation Sciences Research Group and Discipline of Physiotherapy, University of Sydney, Sydney, Australia

${ }^{2}$ Department of Medicine, St Joseph's Health Care Centre, Toronto, Canada ${ }^{3}$ Department of Rehabilitation, Reade, Centre for Rehabilitation and Rheumatology, Amsterdam, The Netherlands

${ }^{4}$ Department of Physiotherapy, Melbourne School of Health Sciences, University of Melbourne, Melbourne, Australia

\section{Correspondence to} Dr Martin Van der Esch, Department of Rehabilitation, Reade, Centre for Rehabilitation and Rheumatology, dr. J. van Breemenstraat 2, Amsterdam 1056AB, The Netherlands; m.vd.esch@reade.nl

This review is an abridged version of a Cochrane Review previously published in the Cochrane Database of Systematic Reviews 2015;1: 10.1002/14651858.CD004376 (see www.thecochranelibrary. com for information).

Accepted 17 August 2015 Published Online First 24 September 2015

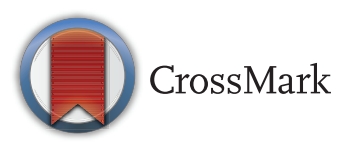

To cite: Fransen $M$, McConnell S, Harmer AR, et al. Br J Sports Med 2015:49:1554-1557.

\title{
Exercise for osteoarthritis of the knee: a Cochrane systematic review
}

\author{
Marlene Fransen, ${ }^{1}$ Sara McConnell, ${ }^{2}$ Alison R Harmer, ${ }_{1}^{1}$ Martin Van der Esch, ${ }^{3}$ \\ Milena Simic, ${ }^{1}$ Kim L Bennell ${ }^{4}$
}

\section{ABSTRACT \\ Objective To determine whether land-based} therapeutic exercise is beneficial for people with knee osteoarthritis $(\mathrm{OA})$ in terms of reduced joint pain or improved physical function and quality of life.

Methods Five electronic databases were searched, up until May 2013. Randomised clinical trials comparing some form of land-based therapeutic exercise with a non-exercise control were selected. Three teams of two review authors independently extracted data and assessed risk of bias for each study. Standardised mean differences immediately after treatment and 2-6 months after cessation of formal treatment were separately pooled using a random effects model.

Results In total, 54 studies were identified. Overall, 19 (35\%) studies reported adequate random sequence generation, allocation concealment and adequately accounted for incomplete outcome data. However, research results may be vulnerable to selection, attrition and detection bias. Pooled results from 44 trials indicated that exercise significantly reduced pain (12 points/100; $95 \% \mathrm{Cl} 10$ to 15$)$ and improved physical function (10 points/100; $95 \% \mathrm{Cl} 8$ to 13 ) to a moderate degree immediately after treatment, while evidence from 13 studies revealed that exercise significantly improved quality of life immediately after treatment with small effect (4 points/100; 95\% Cl 2 to 5). In addition, 12 studies provided 2-month to 6-month post-treatment sustainability data which showed significantly reduced knee pain (6 points/100; 95\% Cl 3 to 9) and 10 studies which showed improved physical function (3 points/100; 95\% Cl 1 to 5).

Conclusions Among people with knee osteoarthritis, land-based therapeutic exercise provides short-term benefit that is sustained for at least 2-6 months after cessation of formal treatment.

\section{INTRODUCTION}

Osteoarthritis (OA), the most common rheumatic disease, primarily affects the articular cartilage and the subchondral bone of a synovial joint, eventually resulting in joint failure. People with progressive symptomatic knee OA experience pain and increasing difficulty with daily functional activities. In fact, knee OA bears more responsibility than any other disease for disability in walking, stair climbing and housekeeping. ${ }^{1-3}$ Currently, no cure for OA is known. However, disease-related factors, such as impaired muscle function and reduced fitness, are potentially amenable to exercise therapy. ${ }^{45}$

Exercise therapy takes a multitude of forms and results in numerous systemic and local effects, some of which have been investigated among people with knee OA. Therapeutic exercise covers a range of targeted physical activities that directly aim to improve muscle strength, neuromotor control, joint range of motion and aerobic fitness. One of the main aims of exercise is to improve muscle strength, given that weakness is common in knee OA. Strength training of sufficient dosage can address muscle weakness by improving muscle mass and/or recruitment. However, among patient groups, pain must be considered and may be a barrier, hence leading to underdosage of the strength stimulus. Enhanced strength of the lower limb may lessen internal knee forces, reduce pain and improve physical function. ${ }^{6-8}$ Increased muscle strength may modify biomechanics, resulting in a decreased joint loading rate or localised stress in the articular cartilage, thereby playing an important role in delaying initiation and ameliorating progression of knee OA. ${ }^{9-14}$ Improved fitness may enhance quality of life by allowing a greater range of available daily tasks, thereby improving physical function.

The objective of this systematic review was to determine whether land-based therapeutic exercise is beneficial for people with knee OA in terms of reduced joint pain or improved physical function and quality of life.

\section{METHODS}

The search strategy identified all randomised or quasi-randomised controlled trials (RCTs), published in the English language, that compared a group undertaking some form of land-based therapeutic exercise with a non-exercise group. Participants given an established diagnosis of knee OA according to accepted criteria, ${ }^{15}$ or who selfreported knee OA on the basis of chronic joint pain (with or without radiographic confirmation) were included. Any land-based non-perioperative therapeutic exercise regimens aimed at relieving the symptoms of OA, regardless of content, duration, frequency or intensity were included. The comparator (control) group could be an active (given any non-exercise intervention) or no treatment (including waiting list) group.

In accordance with international consensus regarding the core set of outcome measures for phase III clinical trials in OA, ${ }^{16}$ each RCT had to include assessment of at least one of the following criteria: (1) knee pain, (2) self-reported physical function and (3) quality of life. If provided, the number of participants experiencing adverse events was noted.

Five electronic databases were searched from inception to May 2013: MEDLINE, EMBASE, the 
Cochrane Central Register of Controlled Trials (CENTRAL), the Cumulative Index to Nursing and Allied Health Literature (CINAHL) and the Physiotherapy Evidence Database (PEDro). Also included was a search of ClinicalTrials.gov (http://www. ClinicalTrials.gov) and the WHO trials portal (http://www.who. int/ictrp/en/).

Three teams of two review authors (MF, SMcC, ARH, MVdE, MS, KLB) independently screened retrieved clinical studies for inclusion. If agreement was not achieved at any stage, a third review author from one of the other two teams adjudicated. Those teams extracted data from all included studies and conducted the risk of bias assessment. If agreement was not achieved at any stage, a third review author from one of the other two teams adjudicated. If a trial provided data from more than one pain scale, data were extracted from the pain scale that was highest on a list according to a previously described hierarchy of pain-related outcomes. ${ }^{17} 18$ Data on more than one physical function scale, when reported in a trial, were extracted according to a hierarchy format (eg, WOMAC or other functional scale). If data on more than one quality of life scale were reported in a trial, data were extracted according to a hierarchy format (eg, SF-12 or other quality of life scale). Risk of bias was assessed in accordance with methods recommended by The Cochrane Collaboration. Each potential source of bias was graded as high, low or unclear. If random sequence generation, allocation concealment and incomplete outcome data domains were adequately met by a study, the overall risk of bias on pain and physical function was judged as 'low' for that study. All other studies were categorised as 'unclear' or 'high' risk of bias. If participants were stated to be blinded to treatment allocation, the study was considered as low risk for detection bias on pain and physical function.

As studies used a variety of continuous scales to evaluate pain, physical function and quality of life outcomes, a unit-less measure of treatment effect size was needed to allow the results of various RCTs to be combined. Standardised mean differences (SMDs) were used to calculate treatment effect sizes from the end of treatment, or change scores and related SD scores, when possible. Treatment effect size therefore is a unit-less measure providing an indication of size of effect in terms of its variability. Outcomes pooled using SMDs were re-expressed as equivalent mean differences by multiplying by a representative control group (high weighting in pooled analyses) baseline SD. The Mantel-Haenszel OR was pooled to calculate the effects of treatment allocation on study withdrawal before the first outcome assessment.

Heterogeneity was assessed in a random-effects model, and overall effects were adjusted to include an estimate of the degree of variation between studies, or heterogeneity, in intervention effect $\left(\tau^{2}\right) .{ }^{19}$ The impact of heterogeneity on meta-analysis results was quantified by the $\mathrm{I}^{2}$ statistic. This statistic describes the percentage of variability in effect estimates that is due to heterogeneity rather than to chance ${ }^{19}: 30-60 \%$ probably represents moderate heterogeneity, and $>50 \%$ is usually considered as representing substantial heterogeneity. For studies published after 1 July 2005, the Clinical Trials Register at the International Clinical Trials Registry Platform of the WHO (http://apps.who.int/ trialssearch) was screened to obtain the a priori trial protocol. The GRADEpro software and the five GRADE (Grades of Recommendation, Assessment, Development and Evaluation) considerations (study limitations, consistency of effect, imprecision, indirectness and publication bias) were used to assess the quality of a body of evidence for stated outcomes. ${ }^{20}{ }^{21}$ Finally, with sensitivity analysis, the effects of (1) potential selection and attrition bias on immediate posttreatment pain and physical function outcomes and (2) the effect of potential detection bias on immediate post-treatment pain and physical function outcomes were assessed.

Subgroup analyses were conducted to determine the sustainability of treatment effects, as well as to determine if the size of treatment effect was mediated by exercise content, number of face-to-face sessions or the method of treatment delivery.

\section{RESULTS}

\section{Study characteristics}

Of 212 retrieved RCTs identified by the literature search, 54 met the inclusion criteria. ${ }^{22-75}$ Among these, marked variability was noted with regard to study participants recruited, timing of outcomes assessments, exercise interventions assessed and important aspects of study methodology. Most studies recruited between 50 and 150 participants. However, 19 (35\%) studies recruited fewer than 25 participants in one or both allocation groups, ${ }^{23-25} \quad 29-31 \quad 35 \quad 3950 \quad 5258 \quad 59 \quad 63-69$ whereas five studies recruited more than 200 participants, 2245484970 one of which recruited 750 participants. $^{70}$

Sample recruitment varied widely, with studies recruiting exclusively community volunteers, ${ }^{23} 26272934363844495360-$ 626474 patients drawn from specialist rheumatology or orthopaedic clinics, ${ }^{28} 30333546475466687175$ a mix of community volunteers and patients from specialist clinics or patients referred by general practitioners. ${ }^{22} 254850$

A wide range of therapeutic exercise programmes were assessed. Variability was found in delivery mode, type of exercise, and treatment 'dosage' (duration, frequency, intensity) and many studies did not provide a clear rationale for their choice. With regard to treatment duration, monitored treatment sessions, presented in individual or class-based format, ranged from 20 to $60 \mathrm{~min}$. Exercise frequency for monitored classes or for individual clinic sessions in most studies was two to three times per week but varied between one 2841497275 to five times per week. ${ }^{23}$ Intensity achieved during strength training using free or limb weights or Theraband was commonly a 10 -repetition maximum with varying numbers of sets ${ }^{27} 313453$ or was at least moderate. ${ }^{30} 7274$ Aerobic exercise training, achieved via walking or cycling programmes, ranged from low $^{2569}$ to moderate 3437445057596164 intensity.

According to the methodological quality assessment, a total of 19 of 54 studies (35\%) could be considered as achieving 'low risk of bias' from the published report. ${ }^{22} 24 \quad 263435 \quad 373848$ 52-55 576270717374 Only 4 of the 54 included studies claimed blinding of study participants. ${ }^{26} 313662$

Pooled results of 44 studies (see online supplementary table S1) demonstrated statistically significant benefit of exercise on pain immediately post-treatment, with an SMD of 0.49 (95\% CI 0.39 to 0.59 ). This effect size would be considered moderate $^{76}$ and was equivalent to a reduction of 12 points (95\% CI 10 to 15 points) on a 0 to 100 -point pain scale ( 0 indicating no pain). Between-study heterogeneity was moderate $\left(\mathrm{I}^{2}=47 \%\right)$. No significant difference was noted between the SMD extrapolated from change scores and from end of treatment scores $\left(\mathrm{p}=0.77 ; \mathrm{I}^{2}=0 \%\right)$.

Pooled results of 44 studies (see online supplementary table S2) demonstrated statistically significant benefit of exercise on physical function immediately post-treatment, with an SMD of 0.52 (95\% CI 0.39 to 0.64 ). This effect size would be considered moderate ${ }^{76}$ and was equivalent to an improvement of 10 points (95\% CI 8 to 13 points) on a $0-100$-point scale. Between-study heterogeneity was substantial $\left(\mathrm{I}^{2}=68 \%\right)$. No 
significant difference was noted between change and end of treatment scores $\left(\mathrm{p}=0.36 ; \mathrm{I}^{2}=0 \%\right)$.

Pooled results of 13 studies (see online supplementary table S3) demonstrated statistically significant benefit of exercise on quality of life immediately post-treatment, with an SMD of 0.28 (95\% CI 0.15 to 0.40$)$. This effect size would be considered small ${ }^{76}$ and was equivalent to an improvement of four points (95\% CI 2 to 5 points) on a 0-100-point scale. Between-study heterogeneity was negligible $\left(\mathrm{I}^{2}=0 \%\right)$. No significant difference was noted between change scores and end of treatment scores $\left(\mathrm{p}=0.86 ; \mathrm{I}^{2}=0 \%\right)$.

Pooled results from 12 studies 263040444548556062697577 demonstrated a statistically significant benefit (SMD 0.24, 95\% CI 0.14 to 0.35 ) of exercise on pain at 2-6 months postexercise training. This effect size would be considered small and was equivalent to a reduction of six $(95 \%$ CI 3 to 9) points on a $0-$ 100 -point scale. There was no between-study heterogeneity $\left(\mathrm{I}^{2}=0 \%\right)$. No significant difference was noted between change scores and end of treatment scores $\left(\mathrm{p}=0.40 ; \mathrm{I}^{2}=0 \%\right)$.

In 10 studies, 26304044455560627577 pooled results demonstrated a statistically significant benefit (SMD 0.15, 95\% CI 0.04 to 0.26 ) of exercise on physical function at 2-6 months postexercise training. This effect size would be considered small and was equivalent to an improvement of 3 (95\% CI 1 to 5) points on a $0-100$-point scale. There was no between-study heterogeneity $\left(\mathrm{I}^{2}=0 \%\right)$. No significant difference was noted between change scores and end of treatment scores $(p=0.95$; $\left.\mathrm{I}^{2}=0 \%\right)$.

In six studies, ${ }^{22} 4243586370$ a non-significant effect (SMD $0.08,95 \% \mathrm{CI}-0.15$ to 0.30 ) on pain after more than 6 months was found. The between-study heterogeneity was moderate $\left(\mathrm{I}^{2}=43 \%\right)$. No significant difference was noted between change scores and end of treatment scores $\left(\mathrm{p}=0.95 ; \mathrm{I}^{2}=0 \%\right)$. Pooled results of seven studies 22424358596370 demonstrated statistically significant benefit (SMD 0.20 , 95\% CI 0.08 to 0.32 ) on physical function after more than 6 months. Between-study heterogeneity was absent $\left(\mathrm{I}^{2}=0 \%\right)$. No significant difference was noted between change scores and end of treatment scores $\left(\mathrm{p}=0.95 ; \mathrm{I}^{2}=0 \%\right)$.

The magnitude of the immediate treatment effect for both pain and physical function increased with the number of face-to-face contact occasions with the healthcare professional supervising or monitoring the exercise programme. However, the difference between fewer than 12 occasions and 12 or more occasions failed to reach statistical significance for pain $(p=0.15)$ and for physical function $(p=0.09)$, respectively. Pooled analysis demonstrated that each of the treatment delivery modes (ie, individual treatments, class-based programmes, and 'home' programmes) provided significant reductions in pain and physical function but with no significant difference between the modes for pain $(p=0.14)$ or physical function $(p=0.06)$. While each type of exercise (quadriceps strengthening only, lower limb strengthening, combination strengthening and aerobic exercise, walking programmes and 'others') reduced pain and improved physical function, there was no statistical difference between the exercise training types on pain $(p=0.37)$ and physical function $(\mathrm{p}=0.09)$.

Only 11 RCTs specifically reported on adverse events. $^{22} 26313536384547535573$ All reported events were related to increased back, hip or knee pain among participants allocated to exercise. No serious adverse events were reported in any of the included studies.

Sensitivity analyses showed that the risk of selection and attrition bias was 'low' in 14 studies (1458 participants) for pain and for physical function $(14$ studies, 1456 partici-

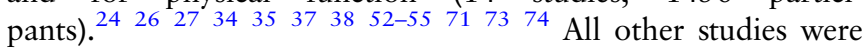
categorised as 'unclear' or 'high' risk of bias (30 studies, 2029 and 2457 participants, respectively). The risk of detection bias for pain and physical function was 'low' in three studies with 226 participants, ${ }^{263136}$ indicating that participants were stated to be blinded to treatment allocation. All other included studies were categorised as 'unclear' or 'high' risk of bias (41 studies, 3261 and 3687 participants, respectively).

\section{DISCUSSION}

This systematic review is an update of a previous Cochrane review, published in 2008, which included 32 RCTs. An additional 22 RCTs have been included in this update for a total of 54 trials, providing data from 5362 participants for outcomes on pain and from 5222 participants for outcomes on physical function. Overall, meta-analysis demonstrated that land-based therapeutic exercise programmes resulted in an immediate mean treatment benefit for knee pain, physical function and quality of life. These mean immediate treatment benefits, extracted from 44 RCTs involving 3537 participants for pain and 3913 participants for physical function, would be considered moderate. Treatment benefit for quality of life, extracted from 13 trials involving 1073 participants, would be considered small. The benefit for pain is comparable with reported estimates for current simple analgaesics and non-steroidal anti-inflammatory drugs taken for knee pain. ${ }^{77}$ Similar results were found for physical function when restricted to the 14 studies, with a total of 1456 participants, evaluated as having low risk of bias. The pain-relieving benefit of exercise declined at 2-6 months postexercise but was still significant, as evidenced in 12 studies involving 1468 participants. However, pain benefits were lost longer than 6 months postexercise, as was found in six studies. A small but significant treatment benefit for physical function remained 2-6 months following exercise, as extracted from 10 studies involving 1279 participants, as well as at time points longer than 6 months, as evidenced in seven studies. These results suggest that although the pain-relieving benefit of exercise therapy is not maintained six or more months after treatment, improvements in physical function are better sustained.

This review highlighted the variety in content of exercise programmes. A range of exercise types can be utilised in clinical practice, with lower limb muscle strengthening and general aerobic exercise recommended by most international guidelines. ${ }^{1277}$ Few studies have attempted to directly compare different types of exercise. One study compared aerobic walking and muscle strengthening, but lack of study power for this particular research question led to inconclusive results. ${ }^{34}$ Two other studies compared different strengthening regimens: weight bearing quadriceps exercises versus non-weight bearing quadriceps exercises in one study, ${ }^{47}$ and concentric-eccentric strengthening exercises versus isometric strengthening exercises in the other. ${ }^{65}$ Neither study found significant differences in effect between types of strengthening exercises. It is interesting to note that meta-analyses also could not demonstrate significant differences in the magnitude of treatment effects for pain and physical function between the various exercise programmes. However, for both pain and physical function, exercise programmes classified as 'other' (which included Tai Chi or complex non-specific exercise programmes involving coordination, stretching or balancing exercises) yielded small benefits and seemed to be less effective than strengthening and aerobic exercise.

The magnitude of the treatment effect for pain and physical function was influenced by the delivery mode such as the 
number of face-to-face contact occasions with the healthcare professional who was supervising or monitoring the exercise programme. However, unlike in the previous Cochrane review, ${ }^{8}$ the difference between fewer than 12 and 12 or more occasions failed to reach statistical significance; this is likely due to considerable between study heterogeneity. Taken together, results suggest that most people with knee OA need some form of ongoing monitoring or supervision to optimise clinical benefits of exercise treatment.

Exercise 'dosage,' which is a factor of programme duration, frequency and intensity, varied considerably between the studies included in this review. Even if dosages were similar, uncertainty may still be inherent. Prescribed dosage may not be translated into actual dosage as it is dependent on individual effort (and hence intensity) during each session; and prescribed dosage is also dependent on effort during testing and retesting sessions. The influence of programme duration on dosage is difficult to quantify, with simple addition not providing a sufficient physiologically plausible model. Only one of the included studies attempted to evaluate the influence of exercise dosage on outcomes by comparing high-intensity and low-intensity resistance training of the knee flexor and extensor muscles while controlling for total exercise workload. ${ }^{46}$ That study found no difference between high-intensity and low-intensity strength training in improving clinical effects.

Overall quality of the body of evidence was assessed as high when the GRADE approach was applied for pain and quality of life. Although selection, attrition and detection bias may have resulted in overestimation of the effect sizes, we did not consider it substantial enough to downgrade the evidence. Evidence underpinning physical function was moderate and was downgraded because of imprecision (marked heterogeneity between study findings). For immediate post-treatment pain and physical function, 14 of 42 studies (33\%) were categorised as having low risk of selection and attrition bias (random sequence generation, allocation concealment and incomplete outcome data domains adequately met).

Treatment effect size for many of the studies was modest. Multifaceted interventions that incorporate exercise strategies into patient care may provide greater benefit and should be tested. Future studies are needed to: (1) identify possible predictors of patient responsiveness to therapeutic exercise, such as radiographic disease severity, symptom duration, outcomes expectancy, psychological well-being, obesity, knee stability, etc, (2) develop multiarmed placebo-controlled RCTs to help provide evidence of optimal exercise content and dosage, and (3) assess the long-term effectiveness of exercise for people with knee OA in terms of structural disease progression.

Some important caveats to this review must be stated. First, given that the comparator in many studies was a no-treatment control group, and that blinding of participants was not performed in almost all trials, the well-documented strong placebo effects for self-reported outcomes in knee $\mathrm{OA}^{78}$ have not been controlled for in the exercise studies. Thus it is not possible to determine the exact magnitude of beneficial effects directly arising from exercise per se. The second issue concerns the responsiveness of self-reported pain and physical function measures. Many of the studies included in this systematic review recruited a majority of participants with early or mild symptomatic disease. Although people with early disease frequently demonstrate reduced muscle strength and aerobic capacity compared with their age-matched and gender-matched peers without symptomatic OA, these physiological impairments often are not yet large enough to translate into reportable difficulties on simple questionnaires. Lack of reportable difficulties would considerably reduce the potential range of improvement that was possible (ceiling effect) on self-report questionnaires among people with early or mild disease.

Several limitations of this review have been identified. Although we conducted an extensive literature search, because resources were limited, we extracted data only from studies published in the English language, potentially excluding other important evidence. Four studies were published in a language other than English, ${ }^{79-82}$ and we were unable to source full text for two studies. ${ }^{83} 84$ These studies await classification. However, the possibility of publication bias could not be excluded, as we did not attempt to retrieve unpublished studies. The effectiveness of exercise was investigated only for measures of self-reported pain, physical function and quality of life. However, regular exercise has been demonstrated to offer many other overall physical and mental health benefits, apart from those related to OA-induced disease impairments. Therefore this review likely underestimates the overall beneficial effects of exercise amongst people with knee $\mathrm{OA}$, which is consistent with previously published systematic reviews. ${ }^{85}{ }^{86}$ Mediating effects of exercise dosage and disease severity on the effectiveness of exercise could not be ascertained because of large variability in reported data.

\section{Conclusions}

High-quality evidence suggests that land-based therapeutic exercise provides benefit in terms of reduced knee pain and improved quality of life and moderate-quality evidence of improved physical function among people with knee OA. Healthcare professionals and people with OA can be reassured that any type of exercise programme that is performed regularly and is closely monitored by healthcare professionals can improve pain, physical function and quality of life related to knee OA in the short term.

\section{What are the new findings?}

- High-quality evidence suggests that land-based therapeutic exercise provides benefit in terms of reduced knee pain and improved quality of life and moderate-quality evidence of improved physical function among people with knee osteoarthritis.

- It can be assured that any type of exercise programme that is performed regularly and is closely monitored can improve pain, physical function and quality of life related to knee $O A$ in the short term.

- The magnitude of immediate treatment effects of exercise on pain and physical function increases with the number of face-to-face contact occasions with the healthcare professional.

- Mediating effects of exercise dosage and disease severity on the effectiveness of exercise could not be ascertained because of large variability in reported data.

\section{Competing interests None.}

Provenance and peer review Not commissioned; internally peer reviewed.

\section{REFERENCES}

1 Davis MA, Ettinger WH, Neuhaus JM, et al. Knee osteoarthritis and physical functioning: evidence from the NHANES 1 epidemiologic followup study. J Rheumatol 1991;18:591-8. 
2 Guccione AA, Felson DT, Anderson JJ, et al. The effects of specific medical conditions on the functional limitations of elders in the Framingham study. Am J Public Health 1994;84:351-8.

3 van Dijk GM, Dekker J, Vennhof C, et al. Course of functional status and pain in osteoarthritis of the hip or knee: a systematic review of the literature. Arthritis Rheum 2006;55:779-85.

4 Buchner DM, Beresford SAA, Larson EB, et al. Effects of physical activity on health status in older adults II: Intervention studies. Ann Rev Publ Health

1992;13:469-88.

5 Fiatarone MA, Evans WJ. The etiology and reversibility of muscle dysfunction in the aged. J Gerontol 1993;48:77-83.

6 Bennell KL, Hunt MA, Wrigley TV, et al. Role of muscle in the genesis and management of knee osteoarthritis. Rheum Dis Clin North Am 2008;34:731-54.

7 Dekker J. Exercise and physical functioning in osteoarthritis; medical, neuromuscular and behavioral perspectives. Berlin: Springer-Verlag, 2013.

8 Fransen M, McConnell S, Harmer AR, et al. Exercise for osteoarthritis of the knee. Cochrane Database Syst Rev 2015;1:CD004376.

9 Cooper C. Occupational activity and the risk of osteoarthritis. J Rheumatol 1995:22:10-12.

10 Felson DT. Weight and osteoarthritis. J Rheumatol 1995;22:7-9.

11 Kujala UM, Kettunen J, Paananen $\mathrm{H}$, et al. Knee osteoarthritis in former runners, soccer players, weight lifters, and shooters. Arthritis Rheum 1995;38:539-46.

12 McAlindon TE, Bannuru RR, Sullivan MC, et al. OARSI guidelines for the non-surgical management of knee osteoarthritis. Osteoarthr Cartil 2014;22:363-88.

13 Slemenda C, Brandt KD, Heilman DK, et al. Quadriceps weakness and osteoarthritis of the knee. Ann Intern Med 1997;127:97-104.

14 Zhang Y, Glynn RJ, Felson D. Musculoskeletal disease research: should we analyze the joint or the person? J Rheumatol 1996:23:1130-4.

15 Altman RD. Criteria for the classification of clinical osteoarthritis. J Rheumatol 1991;18(Suppl 27):10-12.

16 Bellamy N, Kirwan J, Boers $M$, et al. Recommendations for a core set of outcome measures for future phase III clinical trials in knee, hip and hand osteoarthritis. Consensus development at OMERACT III. J Rheumatol 1997;24:799-802.

17 Jüni $P$, Reichenbach S, Dieppe P. Osteoarthritis: rational approach to treating the individual. Best Pract Res Clin Rheumatol 2006;20:721-40.

18 Reichenbach S, Sterchi R, Scherer M, et al. Meta-analysis: chondroitin for osteoarthritis of the knee or hip. Ann Intern Med 2007:146:580-90.

19 Deeks JJ, Higgins JPT, Altman DG. Chapter 9: Analysing data and undertaking meta-analyses. In: Higgins J, Green S, eds. Cochrane Handbook for Systematic Reviews of Interventions Version 5.0.2: The Cochrane Collaboration. The Cochrane Collaboration, 2011. http://www.cochrane-handbook.org

20 Schünemann HJ, Oxman AD, Higgins JPT, et al. Chapter 11: Presenting results and 'Summary of findings' tables. In: Higgins JPT, Green S, eds. Cochrane Handbook for Systematic Reviews of Interventions Version 5.1.0 [updated March 2011]. The Cochrane Collaboration, http://www.cochrane-handbook.org

21 Schünemann HJ, Oxman AD, Vist GE, et al. Chapter 12: Interpreting results and drawing conclusions. In: Higgins JPT, Green S, eds. Cochrane Handbook for Systematic Reviews of Interventions Version 5.1.0 [updated March 2011]. The Cochrane Collaboration, 2011. http://www.cochranehandbook.org

22 Abbott JH, Robertson MC, Chapple C, et al. Manual therapy, exercise therapy, or both, in addition to usual care, for osteoarthritis of the hip or knee: a randomized controlled trial. I: Clinical effectiveness. Osteoarthr Cartil 2013:21:525-34.

23 An B, Dai K, Zhu Z, et al. Baduanjin alleviates the symptoms of knee osteoarthritis. J Altern Complement Med 2008;14:167-74.

24 Baker KR, Nelson ME, Felson DT, et al. The efficacy of home based progressive strength training in older adults with knee osteoarthritis: a randomized controlled trial. J Rheumatol 2001;28:1655-65.

25 Bautch JC, Malone DG, Vailas AC. Effects of exercise on knee joints with osteoarthritis: a pilot study of biologic markers. Arthritis Care Res 1997;10:48-55.

26 Bennell KL, Hinman RS, Metcalf BR, et al. Efficacy of physiotherapy management of knee joint osteoarthritis: a randomised, double blind, placebo controlled trial. Ann Rheum Dis 2005;64:906-12

27 Bennell KL, Hunt MA, Wrigley TV, et al. Hip strengthening reduces symptoms but not knee load in people with medial knee osteoarthritis and varus malalignment: a randomised controlled trial. Osteoarthr Cartil 2010;18:621-8.

28 Bezalel T, Carmeli E, Katz-Leurer M. The effect of a group education programme on pain and function through knowledge acquisition and home-based exercise among patients with knee osteoarthritis: a parallel randomised single-blind clinical trial. Physiotherapy 2010;96:137-43.

29 Brismée J, Paige RL, Chyu M, et al. Group and home-based Tai Chi in elderly subjects with knee osteoarthritis: a randomized controlled trial. Clinic Rehab 2007;21:99-111.

30 Bruce-Brand RA, Walls RJ, Ong JC, et al. Effects of home-based resistance training and neuromuscular electrical stimulation in knee osteoarthritis: a randomized controlled trial. BMC Musculoskelet Dis 2012;13:118.

31 Chang TF, Liou TH, Chen $\mathrm{CH}$, et al. Effects of elastic-band exercise on lower-extremity function among female patients with osteoarthritis of the knee. Disabil Rehabil 2012;34:1727-35.
32 Deyle GD, Henderson NE, Matekel RL, et al. Effectiveness of manual physical therapy and exercise in osteoarthritis of the knee. Ann Intern Med 2000;132:173-81.

33 Doi T, Akai M, Fujino $\mathrm{K}$, et al. Effect of home exercise of quadriceps on knee osteoarthritis compared with nonsteroidal antiinflammatory drugs: a randomized controlled trial. Am J Physic Med Rehabil 2008;87:258-69.

34 Ettinger WH, Burns R, Messier SP, et al. A randomized trial comparing aerobic exercise and resistance exercise with a health education program in older adults with knee osteoarthritis. The Fitness Arthritis and Seniors Trial (FAST). JAMA 1997:277:25-31.

35 Foley A, Halbert J, Hewitt T, et al. Does hydrotherapy improve strength and physical function in patients with osteoarthritis - a randomised controlled trial comparing a gym based and a hydrotherapy based strengthening programme. Ann Rheum Dis 2003:62:1162-7.

36 Foroughi N, Smith RM, Lange AK, et al. Lower limb muscle strengthening does not change frontal plane moments in women with knee osteoarthritis: a randomized controlled trial. Clin Biomech 2011;26:167-74.

37 Fransen M, Crosbie J, Edmonds J. Physical therapy is effective for patients with osteoarthritis of the knee: a randomized controlled trial. J Rheumatol 2001;28:156-64.

38 Fransen M, Nairn L, Winstanley J, et al. Physical activity for osteoarthritis management: a randomised controlled clinical trial evaluating hydrotherapy and Tai Chi classes. Arthritis Care Res 2007;57:407-14.

39 Gür H, Çakin N, Akova B, et al. Concentric versus combined concentric-eccentric isokinetic training: effects on functional capacity and symptoms in patients with osteoarthrosis of the knee. Arch Phys Med Rehabil 2003;83:308-16.

40 Hay EM, Foster NE, Thomas E, et al. Effectiveness of community physiotherapy and enhanced pharmacy review for knee pain in people aged over 55 presenting to primary care: pragmatic randomised trial. BMJ 2006:333:995

41 Hopman-Rock M, Westhoff $M$. The effects of a health educational and exercise program for older adults with osteoarthritis of the hip or knee. J Rheumatol 2000:27:1947-54.

42 Huang $\mathrm{M}-\mathrm{H}$, Lin $\mathrm{Y}-\mathrm{S}$, Yang R-C, et al. A comparison of various therapeutic exercises on the functional status of patients with knee osteoarthritis. Semin Arthritis Rheum 2003;32:398-406.

43 Huang $\mathrm{M}-\mathrm{H}$, Yang R-C, Lee $\mathrm{C}-\mathrm{L}$, et al. Preliminary results of integrated therapy for patients with knee osteoarthritis. Arthritis Care Res 2005;53:812-20.

44 Hughes SL, Seymour RB, Campbell R, et al. Impact of the Fit and Strong intervention on older adults with osteoarthritis. Gerontologist 2004;44:217-28.

45 Hurley MV, Walsh NE, Mitchell HL, et al. Clinical effectiveness of a rehabilitation program integrating exercise, self-management, and active coping strategies for chronic knee pain: a cluster randomized trial. Arthritis Rheum 2007:57:1211-19.

46 Jan M, Lin J, Liau J, et al. Investigation of clinical effects of high- and low-resistance training for patients with knee osteoarthritis: a randomized controlled trial. Phys Ther 2008;88:427-36.

47 Jan $M$, Lin C, Lin Y, et al. Effects of weight-bearing versus nonweight-bearing exercise on function, walking speed, and position sense in participants with knee osteoarthritis: a randomized controlled trial. Arch Phys Med Rehabil 2009:90:897-904.

48 Jenkinson CM, Doherty M, Avery AJ, et al. Effects of dietary intervention and quadriceps strengthening exercises on pain and function in overweight people with knee pain: randomised controlled trial. BMJ 2009;339:b3170.

49 Kao M-J, Wu M-P, Tsai M-W, et al. The effectiveness of a self-management program on quality of life for knee osteoarthritis (OA) patients. Arch Gerontol Geriatrics 2012;54:317-24.

50 Keefe FJ, Blumenthal J, Baucom D, et al. Effects of spouse-assisted coping skills training and exercise training in patients with osteoarthritic knee pain: a randomized controlled study. Pain 2004;110:539-49.

51 Kovar PA, Allegrante JP, MacKenzie CR, et al. Supervised fitness walking in patients with osteoarthritis of the knee. Ann Intern Med 1992;116:529-34.

52 Lee H-J, Park H-J, Chae Y, et al. Tai Chi Qigong for the quality of life of patients with knee osteoarthritis: a pilot, randomized, waiting list controlled trial. Clinic Rehabil 2009;23:504-11.

53 Lim B-W, Hinman RS, Wrigley TV, et al. Does knee malalignment mediate the effects of quadriceps strengthening on knee adduction moment, pain, and function in medial knee osteoarthritis? A randomized controlled trial. Arthritis Care Res 2008;59:943-51.

54 Lin D, Lin CJ, Lin Y, et al. Efficacy of 2 non-weight bearing interventions, proprioception training versus strength training, for patients with knee osteoarthritis: a randomized clinical trial. J Orthop Sports Phys Ther 2009;39:450-7.

55 Lund $\mathrm{H}$, Weile $\mathrm{U}$, Christensen $\mathrm{R}$, et al. A randomized controlled trial of aquatic and land-based exercise in patients with knee osteoarthritis. J Rehabil Med 2008:40:137-44

56 Maurer BT, Stern AG, Kinossian B, et al. Osteoarthritis of the knee: isokinetic quadriceps exercise versus an educational intervention. Arch Physic Med Rehabil 1999:80:1293-9.

57 Messier SP, Loeser RF, Miller GD, et al. Exercise and dietary weight loss in overweight and obese older adults with knee osteoarthritis. Arthritis Rheum 2004;50:1501-10. 
58 Mikesky AE, Mazzuca SA, Brandt KD, et al. Effects of strength training on the incidence and progression of knee osteoarthritis. Arthritis Care Res 2006;55:690-9.

59 Minor MA, Hewett JE, Webel RR, et al. Efficacy of physical conditioning exercise in patients with rheumatoid arthritis and osteoarthritis. Arthritis Rheum 1989;32:1396-405

60 O'Reilly SC, Muir KR, Doherty M. Effectiveness of home exercise on pain and disability from osteoarthritis of the knee: a randomised controlled trial. Ann Rheum Dis 1999;58:15-19.

61 Péloquin L, Bravo G, Gauthier $P$, et al. Effects of a cross-training exercise program in persons with osteoarthritis of the knee a randomized controlled trial. J Clin Rheumatol 1999;5:126-36.

62 Quilty B, Tucker M, Campbell R, et al. Physiotherapy, including quadriceps exercises and patellar taping, for knee osteoarthritis with predominant patello-femoral joint involvement: randomized controlled trial. J Rheumatol 2003;30:1311-17.

63 Røgind H, Bibow-Nielsen B, Jensen B, et al. The effects of a physical training program on patients with osteoarthritis of the knees. Arch Physic Med Rehabil 1998;79:1421-7.

64 Salacinski AJ, Krohn K, Lewis SF, et al. The effects of group cycling on gait and pain-related disability in individuals with mild-to-moderate knee osteoarthritis: a randomized controlled trial. J Orthop Sports Phys Ther 2012;42:985-95.

65 Salli A, Sahin N, Baskent A, et al. The effect of two exercise programs on various functional outcome measures in patients with osteoarthritis of the knee: a randomized controlled clinical trial. Isokin Exerc Sc 2010;18:201-9.

66 Schilke JM, Johnson GO, Housh TJ, et al. Effects of muscle-strength training on the functional status of patients with osteoarthritis of the knee joint. Nurs Res 1996:45:68-72.

67 Simão AP, Avelar NC, Tossige-Gomes R, et al. Functional performance and inflammatory cytokines after squat exercises and whole-body vibration in elderly individuals with knee osteoarthritis. Arch Phys Med Rehabil 2012;93:1692-700.

68 Song R, Lee E-O, Lam P, et al. Effects of Tai Chi exercise on pain, balance, muscle strength, and perceived difficulties in physical functioning in older women with osteoarthritis: a randomized clinical trial. J Rheumatol 2003;30:2039-44.

69 Talbot LA, Gaines JM, Huynh TN, et al. A homebased pedometer-driven walking program to increase physical activity in older adults with osteoarthritis of the knee: a preliminary study. J Am Geriatr Soc 2003;51:387-92.

70 Thomas KS, Muir KR, Doherty M, et al. Home based exercise programme for knee pain and knee osteoarthritis: randomised controlled trial. BMJ 2002;325:752-7.

71 Thorstensson CA, Roos EM, Petersson IF, et al. Sixweek high-intensity exercise program for middle-aged patients with knee osteoarthritis: a randomized controlled trial [ISRCTN20244858]. BMC Musculoskelet Disord 2005;6:27.

72 Topp R, Woolley S, Horuyak J, et al. The effect of dynamic versus isometric resistance training on pain and functioning among adults with osteoarthritis of the knee. Arch Phys Med Rehabil 2002;83:1187-95.
73 van Baar ME, Dekker J, Oostendorp RAB, et al. The effectiveness of exercise therapy in patients with osteoarthritis of the hip or knee: a randomized clinical trial. J Rheumatol 1998;25:2432-9.

74 Wang TJ, Lee SC, Liang SY, et al. Comparing the efficacy of aquatic exercises and land-based exercises for patients with knee osteoarthritis. J Clin Nurs 2011;20:2609-22.

75 Yip YB, Sit JW, Fung KKY, et al. Impact of an arthritis self-management programme with an added exercise component for osteoarthritic knee sufferers on improving pain, functional outcomes, and use of health care services: an experimental study. Pat Educ Couns 2007;65:113-21.

76 Cohen J. Statistical power analysis for the behavioural sciences. New York: Academic, 1977.

77 Hochberg MC, Altman RD, April KT, et al. American College of Rheumatology 2012 recommendations for the use of nonpharmacologic and pharmacologic therapies in osteoarthritis of the hand, hip, and knee. Arthritis Care Res 2012;64:465-74.

78 Zhang W, Nuki G, Moskowitz RW, et al. OARSI recommendations for the management of hip and knee osteoarthritis: Part III: changes in evidence following systematic cumulative update of research published through January 2009. Osteoarthr Cartil 2010;18:476-99.

79 Carlos KP, Belli BdS, Alfredo PP. Effect of pulsed ultrasound and continuous ultrasound linked to exercise in patients with knee osteoarthritis: pilot study [Portuguese]. Fisioter Pesq 2012;19:275-81.

80 Ghroubi S, Elleuch H, Kaffel N, et al. [Contribution of exercise and diet in the management of knee osteoarthritis in the obese]. Ann Readapt Med Phys 2008;51:663-70

81 Oida Y, Morozumi K, Nakamura N, et al. [Effectiveness of a community health service program using exercise intervention for elderly people with osteoarthritis of the knees: a randomized controlled trial]. Nihon Koshu Eisei Zasshi 2008;55:228-37.

82 Rosa UH, Velásquez Tlapanco J, Lara Maya C, et al. [Comparison of the effectiveness of isokinetic vs isometric therapeutic exercise in patients with osteoarthritis of knee]. Reumatol Clin 2012;8:10-14.

83 Eungpinichpong $W$. The efficacy of physical exercise programmes for patients with osteoarthritis of the knee as determined by clinical and gait parameters. New Zeal J Physiother 1998:26:5.

84 Keogan F, Gilsenan C, Hussey J, et al. Open or closed chain quadriceps exercises in treatment of osteoarthritis of the knee; which is more effective? A blinded randomised controlled trial. Physiother Ireland 2007;28:47-8.

85 Uthman OA, van der Windt DA, Jordan JL, et al. Exercise for lower limb osteoarthritis: systematic review incorporating trial sequential analysis and network meta-analysis. BMJ 2013;347:f5555.

86 Juhl C, Christensen R, Roos EM, et al. Impact of exercise type and dose on pain and disability in knee osteoarthritis: a systematic review and meta-regression analysis of randomized controlled trials. Arthritis Rheumatol 2014;66:622-36. 